\title{
Unconditionally Stable Fully Explicit Finite Difference Solution of Solidification Problems
}

\author{
ROHALLAH TAVAKOLI and PARVIZ DAVAMI
}

DOI: $10.1007 /$ s11663-007-9114-6

(C) The Minerals, Metals \& Materials Society and ASM International 2007

\section{ERRATUM TO: METALLURGICAL AND} MATERIALS TRANSACTIONS 38B (2007) 121-142 DOI 10.1007/S11663-006-9017-Y

Page 132 equation (28) should be corrected to:

$$
\Delta t_{\exp }=\min \left(\frac{\rho_{m a t} c_{m a t} \Delta x^{2}}{2 D k_{m a t}}\right)
$$

Page 132 equation (29) should be corrected to:

$$
\Delta t_{\exp }=\min \left(\frac{\rho_{i, j} c_{i, j} \Delta x^{2}}{2 D k_{i, j}}\right)
$$

Page 132, the first statement below equation (30) should be corrected to:

The stability bound of the explicit time integration is Fo $\leq(2 D)^{-1}$.

ROHALLAH TAVAKOLI and PARVIZ DAVAMI are with the Department of Material Science and Engineering, Sharif University of Technology, Tehran, Iran. Contact e-mail: tav@mehr.sharif.edu.

The online version of the original article can be found under doi: 10.1007/s11663-006-9017-y.

Article published online November 20, 2007. 